\title{
The Culture of Japan: Pushing the Limits of Duality
}

\author{
Nina Konovalova \\ Scientific Research Institute of the Theory and History of Architecture and Urban Planning \\ Central Scientific-Research and Project Institute of the Construction Ministry of the Russian Federation \\ Moscow, Russia \\ phuekirjuko@mail.ru
}

\begin{abstract}
The article expresses the hypothesis that the dual scheme is not applicable for describing a particular area of Japanese culture. The author proposes to introduce a third (central) link to the structure of dual representation. The resulting triad describes the specificities of the Japanese worldview more accurately, as the central link performs the role of the intermediate zone, which demarcates but at the same time absorbs, the polar categories. In the view of Japanese, this is not merely important, but fundamental for understanding any phenomenon. To justify the existence of a central link and its dominant role in the culture of Japan, examples are given from the fields of art culture, architecture, and, of course, the Japanese worldview.
\end{abstract}

Keywords-architecture of Japan; the categories of space; "interspace"; "emptiness"; the "shadow" in architecture

\section{INTRODUCTION}

European scholars studying Japanese culture constantly face a number of serious challenges. After its long selfisolation, when Japan was opened to the world in 1868, it turned out to be one of the least researched countries. "Because of its two centuries of alienation from the rest of the world, even what was collected in the XVI and XVII centuries had been forgotten" [1]. The first descriptions of the Japanese - the travel notes of foreigners - focused on the differences between the unknown and incomprehensible Eastern culture and the European culture. The European way of thinking is dual in its structure. This strict duality of views is still automatically transferred to the culture of Japan when studying it. Ruth Benedict was among the first scholars who attempted to apply a serious and comprehensive approach to study the culture of Japan and the mechanisms of its inner structure. She believed that to describe this culture it is necessary to connect all of the existing opposites into a whole, thus smoothing over the contradictions. To achieve it she used the term "but also": "peaceful, but also warlike," "conservative, but also welcoming innovations", etc. [2] Ruth Benedict stresses that no scholar will add a "but also" clause when describing other nations; only Japanese culture somehow inexplicably combines all of the opposites. One of the key features of Japanese culture is the ability to combine opposites.

This suggests that the dual scheme is not applicable to describe the Japanese worldview. There is a need to introduce a third (central) link to the structure of dual representation. The author offers examples to prove the existence of a central link and its dominant role in the artistic culture, architecture, and Japanese worldview.

\section{THE CATEGORY OF “BETWEENNESS” IN ARCHITECT URE}

The "betweenness" principle in architecture was not only widespread but is endowed with great significance. The blending with the natural environment that creates an effect of openness of edifices is one of the most significant features of Japanese architecture. Although the Japanese house is open to nature, it is absolutely closed to outsiders. Lush gardens which are planted around the house, don't is olate the house itself, but protect the interior much better than the European stone wall with windows facing directly onto a noisy street. An open gallery (engawa) surrounds the traditional house, hiding rooms from prying eyes. "It is intended to express the continuation between nature and architecture, and bring together the various architectural groups" [3]. It is the gallery, bringing together the architecture of Japan and nature which opens the building to nature; at the same time, the gallery introduces nature to the architectural construction. In other words, the gallery is a space between the outer and inner spaces. Such an intermediate zone between the interior and the exterior of traditional Japanese houses serves as a multi-purpose space where one can meet visitors over a cup of tea. However, in the gallery, the visitors are in the garden already but not yet inside the house.

The second level of the intermediate space, the entrance hall (genkan - "dark space" in Japanese), is the area between the main entrance and the living rooms. It psychologically transitions from the outer world to the living rooms. It is there that visitors take off their shoes before entering the house. Genkan was always architecturally distinct particularly when elevated above the ground. Even today, the invitation to a Japanese house sounds like "ascend".

Leading masters of modern Japanese architecture also adhere to the fundamental principles of space organization. This demonstrates the connection to the tradition not only formally but on a deeper level of the most basic schemes of space perception, involving its conceptual and aesthetic components. The greatest contemporary architects, when creating their works, strive to maintain a sense of the spaces that have been historically significant in Japanese culture. For example, Kisho Kurokawa, when describing the idea of 
beauty in Japanese culture, creates his own philosophy of architecture, presenting each piece as a unique artistic image. He deliberately appeals to gray colors and the "gray zones" in the building, placing an emphasis on them. Under the "gray zone" concept, Kurokawa means an intermediate space, which can be attributed neither to external nor to internal; it is the median element that absorbs qualities of the other two [4]. With his work, this architect demonstrates the capabilities of gray colors, mostly renouncing bright colors in favor of more subdued shades of gray. In building the Bank in Fukuoka (1976), an intermediate space is formed by the overhang of the roof over one of the side facades. The architect considers the resulting "gray area" to be corresponding to the same functions as the engawa in the traditional house. As in the cool shade of engawa where one could converse with guests, there is a special atmosphere for communication created in this gray zone of the Bank in Fukuoka. This confirms the continuity of the functional purpose of the Kurokawa's "gray zone" as the gallery that encircles a traditional house.

Kiyonori Kikutake also creates traditionally perceived spaces, highlighting the intermediate areas in his work. That is the interspace that, in the understanding of the master, is on the top of the pyramid of traditional Japanese cultural symbols. This architect sees the interspace area as the most multifaceted and functionally rich. In his projects, Kikutake provides several types of spaces separated by functions. Kikutake always emphasizes the unifying space which, being present in all of his projects, dominates and carries the main semantic and functional load.

He demonstrates the capabilities of the space in both global mega-projects and in buildings of a more modest scale. The global "Houses in the form of a tree" project (1966) was not fully constructed. (In 1994, from its basis, the Sofitel hotel was built in Tokyo, which is extremely interesting for implemented architectural techniques. It was demolished in 2008). Kikutake has focused primarily on the inclusion of a social component in the lifestyle of the big city, speaking against the closure of each family's microcosm and it's inexorably increasing alienation. The structure of the Kikutake house allows the apartment to be highly open to the outside, without sacrificing the private space, while also giving it a higher number of connections. Each of his fivestory blocks had an internal space all the apartments of this block would face. It was meant to give the opportunity for people to gather and socialize.

The reviewed projects of modern Japanese architects show a deep understanding of the functions and aes thetics of space as an architectural object, which dates back to the axiological constituent of the traditional culture of Japan.

\section{THE CATEGORY OF "EMPTINESS" IN ARCHITECTURE}

Emptiness is the main characteristic of the interior of traditional Japanese houses. The Japanese perceive the substance of emptiness as special, expressive, and meaningful. The concept of "emptiness" in Japan is directly related to Buddhism. Emptiness in Buddhism is considered to be a potential possibility of things. According to religious beliefs, the man merges with the Buddha and finds him in one's essence only when merging with the emptiness. The consequence of such perceptions was that emptiness became one of the most important and meaningful moments in art and architecture.

In the technology of ink painting, borrowed by Japan from China, some areas on paper or silk are left intact, creating "emptiness". They embody a type of uncertainty, thereby stimulating the imagination of the viewer. Such a blank background embodied one of the fundamental ideas of Buddhist philosophy, shunyata (emptiness). Therefore, the emptiness holds the ability to influence emotions and feelings, unconsciously being perceived as a model of the universe. This kind of philosophy was formed over the centuries and greatly influenced the aesthetic values of Japanese culture and manifested itself in all the fine arts, ikebana, urban planning and architecture. These are capacious concepts that convey the perception of the Japanese category of emptiness in the Japanese language. For instance, "ma", which has many meanings, including "interval", "pause in the music or the dance", and "moment of silence in the recitation". "Ma" represents empty areas, which, within certain limits, can be given any value. "Ma" plays the role of the semantic gap in different spheres of culture that expresses the antipathy of the Japanese to the "contact" of antagonisms. In the No theater tradition, for example, there is a moment of stillness each time when the image of grief or tragedy dramatically changes to joy. It allows combining antagonisms, smoothening their contradictions, and changing the mood. This is the moment when "ma" reveals itself.

This mindset affects the perception of space. Its changes and the content becomes the basis for the creation of artistic images and architectural works. Thus the empty space spread in architecture and was endowed with a primary value.

\section{THE CATEGORY OF "SHADOW" IN ARCHITECTURE}

As was previously mentioned, the basis of European thinking relies on opposing dual categories, such as "light" and "darkness", or "white" and "black". The images developed over the centuries in Europe have assigned the greater importance to the light origin. Light is idealized; it correlates with insight, and is symbolically seen as the source of knowledge through which a person discovers the world. Consequently, in the darkness dwells all the evil and unclean, which were given an appropriate name - "dark forces". Between the light and darkness, as between white and black, there are intermediates, but they are never accentuated and their semantic content indicates a negative attitude towards them. Perhaps the "greyness" is semantically related to mediocrity and dullness because it carries a connotation of uncertainty since it can be attributed neither to one nor to the other pole. Thus, in Western culture, according to the current binary system of thinking, the shadow is afraid of the light, so it attracts all the negative qualities.

In Japan, key importance is given to a shadow existing between the light and darkness. In Japanese culture, the endowment of meaning to the phenomenon of "shadow" 
appears to be directly related to the Shinto tenet where everything has its own deity (kami) and, therefore, every phenomenon has self-worth.

Artistically, the "shadow" has its own value. The negative attitude toward any extremes and oppositions in the culture of Japan has led to the fact that the concept of "shadow" was given such a significant place among other cultural categories. Combining the light and darkness, the "shadow" becomes a central element which alters the dual scheme usual for Europeans.

Shadow is a mandatory component of a traditional house and the main qualitative characteristic of the galleries surrounding the construction (genkan). The roof of traditional Japanese house, with its big overhang, protects the house not only from rain but also from the scorching sun, in a manner of an umbrella. The house gets cover from the bright, harsh light, so the atmosphere of the penumbra softens the color of things, giving them depth and richness. There is no furniture implied on a gallery so it is literally an empty space embracing a dwelling with shadow. The main semantic load in this case is placed on the empty shadow space.

The desire to obscure, to conceal an object from prying eyes can be found in the location of sacred architecture Shinto shrines, for example. German architect Walter Gropius, visiting Ise and the Parthenon, while admiring these architectural monuments, asked: What are these deep shadows shrouding the Ise, and the radiance emitted by the Parthenon evidence of ? [6] This mystery troubled him as an architect. Therefore, he tried to identify the spatial characteristics of the buildings to get into the core of their differences. In his comparison of these famous works of architecture lies the essential differences of Japanese and Western cultures. The Parthenon, erected on a hilltop to be visible to all, is bathed in sunlight and full of grandeur, while the sanctuary of Ise, surrounded by four high walls, is hidden among the dense forest. The atmosphere of the forest, which suggests a kami deity presence, had a profound impact on the mentality of the Japanese. The Japanese language contains a capacious concept of " oku", meaning depth, or space, hidden from all. There are many other aspects of this concept, but they all reflect the Japanese love for "wrapping the subject", and moving it into the shade. This suggests that the Parthenon is a testament to the confidence that man can conquer nature. Western culture exists on the basis of the subjection of nature, and its transformation and use for human needs. This overcoming of chaos creates order, beauty, and the appropriate world order. This attitude has generated the opposition of "nature-culture" existing in the Western world. In comparison, Japanese culture has formed ideas about the overriding importance of the chaos that gave life to all things, and presumes the inability to conquer nature, and the need to live in harmony with it.

Kenko was the first who spoke about the importance of the concept of the "shadow" in the cultural identity. In his work "Essays in Idleness" (1324), he outlined the basis, the core of the aesthetic ideas of the Japanese, claiming that inner beauty, the splendor of things beautiful is manifested only at night [7]. D. Tanizaki develops the chapter of Kenko's zuihitsu and turns it into an independent work, "In Praise of shadows" (1934), which became extremely popular outside of Japan [8]. Tanizaki considers the "shadow" to be one of the absolute concepts necessary for the existence of Japanese culture. He emphasizes that no one but the Japanese have a full understanding of the "shadow" phenomenon. The main pavilion of Japan at Expo 2005 (Pref. Aichi) is an easily "readable" image of culture. The exhibition hall of the pavilion was shrouded in a bamboo cocoon 90 meters long, 70 meters wide, and 19 meters in height (Arch. H. Hikosaka). It became the largest structure of its kind in the world. The manufacture of this bamboo lattice required approximately 23,000 bamboo trunks, which had to be perfectly level. Just as in traditional Japanese houses where the bamboo lattice screens created a shadow and carried coolness into the room, the bamboo cocoon of the pavilion acted as a natural cooling system. It prevented the scorching sunlight from getting inside while allowing for the wind, nature's cooler, to blow unobtrusively. As well as in the bamboo grove where there it is always twilight, the bamboo cocoon reduced the impact of the sunlight on the building and contributed to the lowering of the temperature inside. Bamboo - the main build ing material of the pavilion - is light and strong, and does not absorb moisture, so it is widely used in the architecture of Japan. Traditional houses often had a roof consisting of multiple layers of bamboo tiles. Such coverings protected a house from the rain completely and was absolutely reliable, as bamboo did not rot in the humid Japanese climate. Damaged parts of the tile roof can be easily replaced if necessary. It is the basic principle of Japanese construction that a structure can live "forever".

By means of the lattice cocoon the pavilion interior had a shaded intermediate space which was designed to play a leading role in the creation of an artistic image of the pavilion. Thus, in one part of the pavilion entrance, the architect has managed to make a brilliant statement of the wisdom of the early Japanese buildings' construction methods. It's safe to say that the cocoon of the main Japanese pavilion at Expo 2005 is one of the largest and most prominent buildings of the exhibition. It was designed to showcase the latest technological advances and traditional construction methods; it was a practical use of the engineering findings, and a blending of modern construction with ancient symbols.

\section{CONCLUSION}

Based on the foregoing, it can be said that Japanese architecture of the contemporary period of history, while being at the forefront of the modern architectural process, naturally includes traditional spatial symbols and categories. Examples of modern Japanese architecture lead to the conclusion that the traditional gradation of space into three elements, with a leading role by a central (median) link shows up very clearly in architecture because of its artistic and spatial components. The space is divided according to its functional-semantic properties (which is confirmed by the continued relevance of the principle of "betweenness" of architecture); by its figurative and symbolic properties (as 
illustrated by the example of the "emptiness" category); and aesthetically (as was demonstrated in the example of the "shadow" category). On the ideological level, differences between two and three elements (which includes a central link) systems of thought are a dramatic contrast. The median area, in the view of the Japanese, will always dominate the two poles. It includes the entire extremes, harmonizes and balances them. It is the guiding principle of the world, contributing to a smooth flow from one to another and to the absence of sharp boundaries. The central link, "pushes out" the framework of duality; it is the philosophical core of the Japanese culture and its symbolic values. This primarily explains the complexity in the study of Japan by Westerners. The first step (which will be the key to understanding) on this path is a rejection of the dual categories in the interpretation of the artistic culture of Japan.

\section{REFERENCES}

[1] M. Venyukov, Sketches of Japan. Saint-Petersburg, 1869, p.5.

[2] R. Benedict, The Chrysanthemum and the Sword: Patterns of Japanese Culture. Boston, 1946.

[3] K. Kurokawa, Metabolism in architecture. Boulder, Colorado, 1977.

[4] K. Kurokawa, Each One a Hero: The Philosophy of Symbiosis. Tokyo, 1997.

[5] O. Berque, Vivre l'espace au Japon. - P.: Presses liv. De France, 1982, p. 63.

[6] W. Gropius, Scope of Total Architecture. New York. Harper and Bros, 1955.

[7] Essays in Idleness: The Tsurezuregusa of Kenkō (translated by W. Gorelyad). Collection: Japanese Zuihitsu. Saint-Petersburg, 1998, p. 456.

[8] D. Tanizaki. In Praise of Shadows. Collection: The world in Japanese. Saint-Petersburg, 2000, p. 209. 